\title{
Research on detection method of leakage rate of rough pumping valve in space environment simulator
}

\author{
Wu Yue ${ }^{1}$, Guo Qingliang ${ }^{1}$, Fang Mingyuan ${ }^{1}$, Sun Juan ${ }^{1}$, Guo Ziyin ${ }^{1}$, Wei Xi ${ }^{1}$ \\ ${ }^{1}$ Beijing Institute of Spacecraft Environment Engineering, Beijing 100094, China;
}

\begin{abstract}
As an important part of the vacuum system in the space environment simulator, the rough pumping system reduces the vacuum degree of the container from atmospheric pressure to the pressure of the high vacuum system when the space environment simulator starts up. As the key equipment of the rough pumping system, the rough pumping valve plays the role of isolating the rough pumping system from the environmental simulator, and its leakage rate has a direct impact on the vacuum degree that the space environment simulator can reach. Therefore, it is very important to detect the leakage rate of the rough pumping valve. In this paper, the leakage rate detection method of the rough pumping valve is introduced, including the valve delivery stage and valve installation stage to the simulator stage, in order to provide some basis for the follow-up valve leakage rate detection work.
\end{abstract}

\section{1 overview}

In order to verify the correctness of the thermal design of the spacecraft and the ability of the thermal control system in each flight stage to adapt to various thermal environments, to determine the optimal thermal control parameters of the thermal control system, and to examine and verify the working ability of the spacecraft, sufficient ground tests must be carried out during the development of the spacecraft. The space thermal environment test of spacecraft is carried out in a space environment simulator, in which vacuum is an indispensable environmental condition ${ }^{[1]}$. The vacuum system of space environment simulator is generally composed of two parts: high vacuum system and rough pumping system. The rough pumping system works when the space environment simulator is started, reducing the vacuum of the container to the pressure that the high vacuum system can start ${ }^{[2]}$. The rough pumping valve, as the key equipment of the rough pumping system, is closed after the rough pumping is finished. After the rough pumping system is isolated from the environment simulator, its leakage rate has a direct influence on the vacuum degree of space environment simulator. Therefore, it is necessary to test the leakage rate of the rough pumping valve to make it meet the requirements and ensure the smooth running of the thermal test ${ }^{[3]}$

\section{Detection method for leakage rate}

Generally speaking, the leakage rate detection of rough pumping valves can be divided into two stages, which are the factory detection of valve manufacturers and the leakage rate detection after the valve is installed on the space environment simulator.

\subsection{Factory leakage rate detection}

After the valve manufacturer completes the valve assembly and debugging, it is required to test the factory leakage rate. The general procedure is as follows:

A) The total leakage rate of the valve can be detected by helium cover method, or vacuum the valve body and then keep static pressure for 30 minutes to observe the change of vacuum degree (after the valve is processed, the inner surface should be processed, and the effect of bleed air can be generally ignored);

B) Open the valve, vacuum the valve body, and use helium mass spectrometry blowing method to detect the leakage rate at the welding seam and valve cover of the valve body. Generally, the single point leakage rate is better than $1.0 \times 10^{-10} \mathrm{~Pa} \cdot \mathrm{m} / \mathrm{s}$;

C) Close the valve and use helium cover method to test the positive sealing performance of the valve plate, that is, fill the non-sealed side (valve plate) with helium to $1000 \mathrm{~Pa}$ first, then fill the air to $10^{5} \mathrm{~Pa}$, the general valve plate leakage rate is better than $1.0 \times 10^{-10} \mathrm{~Pa} \cdot \mathrm{m} / \mathrm{s}$;

D) Similar to the above steps, check valve reverse sealing performance;

E) Close the valve, release the cylinder pressure, and use helium mass spectrometry injection to test the sealing condition of the valve plate and shaft seal;

In space environment simulator, there are many pneumatic flapper valve, which can achieve bidirectional sealing. If the valve selected in design is not bidirectional sealing, C) and D) in the above 
program can be combined to test the sealing performance of single side valve plate only.

\subsection{Valve installation leak rate test}

The valve can be installed on the space environment simulator after the factory leak rate test is qualified. After installation, the installation leak rate test of the valve mainly includes the connection between the seat and the simulator and the connection between the seat and the rough pumping pipeline.

Because the sealing performance of the valve plate is a very important technical index of the valve flapper plate, therefore, in order to be safe and reliable, we will generally recheck the leakage rate of the valve plate in engineering practice, to ensure that the leakage rate meets the requirements after the valve is closed.

The total leakage rate between the valve seat and the simulator and the rough pumping line (generally in flange form) is of concern, so the helium mask method is chosen to detect the total leakage rate at the connection $^{[4]}$. During leak detection, after evacuating the tested container with the auxiliary pump, close the auxiliary valve and open the leak detection valve to connect the tested container with the mass spectrometer chamber that has already pumped the ultimate vacuum. When the instrument reaches the working pressure, with the instrument in leak detection mode, wrap the suspicious parts of the container with a helium cover, then remove the air from the cover and fill it with helium. At this point, an increase in the instrument's output indicates a leak in the part of the helium envelope. The leakage rate indicated by the instrument is the total leakage rate of the area covered by the helium mask ${ }^{[5]}$

Since the leakage rate of the valve plate has been tested before the valve leaves the factory, we use the blowout method to re-check the leakage rate of the valve plate. During leak detection, use the auxiliary pump to pump the tested container to a low vacuum, then close the auxiliary valve, open the throttle valve, communicate the tested container with the leak detector that has been pumped to the limit vacuum beforehand, and use the mass spectrometry leak detector to extract air from the tested container. After the mass spectrometer reaches the working pressure, the instrument is in the leak detection state, helium is then sprayed from the top down at the suspected leak of the container. If there is a leak, the helium is sucked into the container and quickly enters the leak detector, where the leak rate is indicated by the output meter. The deflection of the output meter can determine the leakage rate of the detected hole, and the position of the blowout can determine the position of the detected hole ${ }^{[6-7]}$.

Specific leak detection methods are as follows ${ }^{[8]}$ :

A) Vacuum the simulator, use helium cover method to detect the leakage rate at the connection between the valve and the simulator, and use the spray method to recheck the positive sealing performance of the valve plate;

B) Vacuum the rough pumping line, use helium cover method to detect the leakage rate at the connection between the valve and the crude pumping line, and use the spray method to re-examine the reverse sealing performance of the valve plate.

\section{KM6 space environment simulator rough pumping valve leakage rate detection}

The following is a brief introduction to the leakage rate detection process of the ZBS-800 rough-pumping valve in the KM6 space environment simulator.

\subsection{Factory leakage rate detection}

After the completion of assembly and debugging of ZBS-800 valve, the factory leakage rate detection of valve can be completed according to the steps in 2.1 above. The manufacturer combined the valve reverse sealing performance test with the total leakage rate test and the leakage rate test at the welding seam of the valve body and the valve cover to improve the efficiency. After the above leakage rate test is completed, the valve can be tested for forward sealing performance. After the test is completed, the leakage rate detection system set up will not move, and the compressed air in the valve cylinder will be released. After the gas in the cylinder is fully discharged, the leakage rate detection of shaft seal and valve plate can be carried out.

Figure 1 shows the factory leakage rate test of the valve -- the reverse sealing performance of the valve and the total leakage rate of the valve body, as well as the leakage rate test of the welding seam and bonnet of the valve body.

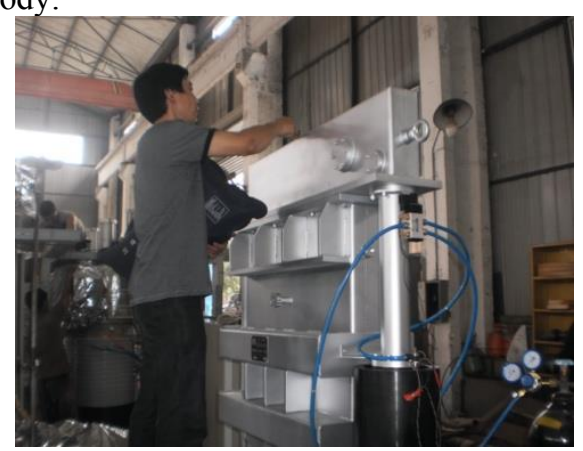

Figure 1 Valve factory leakage rate test site diagram

The leakage rate test results of the valve are shown in Table 1 below. After testing, the leakage rate indexes all meet the technical requirements, and the valve can leave the factory.

Table 1 Detection results of factory leakage rate of valve

\begin{tabular}{|c|c|c|c|c|}
\hline number & $\begin{array}{c}\text { Inspection } \\
\text { items }\end{array}$ & Technical requirements & $\begin{array}{c}\text { Inspection } \\
\text { methods }\end{array}$ & The inspection results \\
\hline
\end{tabular}




\begin{tabular}{|c|c|c|c|c|}
\hline 1 & $\begin{array}{c}\text { The valve } \\
\text { leakage rate }\end{array}$ & $<1.0 \times 10^{-10} \mathrm{~Pa} \cdot \mathrm{m}^{3} / \mathrm{s}$ & Blowing method & $<1.0 \times 10^{-10} \mathrm{~Pa} \cdot \mathrm{m}^{3} / \mathrm{s}$ \\
\hline 2 & $\begin{array}{c}\text { Bonnet } \\
\text { leakage rate }\end{array}$ & $<1.0 \times 10^{-10} \mathrm{~Pa} \cdot \mathrm{m}^{3} / \mathrm{s}$ & Blowing method & $<1.0 \times 10^{-10} \mathrm{~Pa} \cdot \mathrm{m}^{3} / \mathrm{s}$ \\
\hline 3 & $\begin{array}{c}\text { Shaft seal } \\
\text { leakage rate }\end{array}$ & $<1.0 \times 10^{-10} \mathrm{~Pa} \cdot \mathrm{m}^{3} / \mathrm{s}$ & Blowing method & $<1.0 \times 10^{-10} \mathrm{~Pa} \cdot \mathrm{m}^{3} / \mathrm{s}$ \\
\hline 4 & $\begin{array}{c}\text { Reverse } \\
\text { leakage rate of } \\
\text { valve plate }\end{array}$ & $<1.0 \times 10^{-10} \mathrm{~Pa} \cdot \mathrm{m}^{3} / \mathrm{s}$ & $\begin{array}{c}\text { The helium } \\
\text { method }\end{array}$ & $<1.0 \times 10^{-10} \mathrm{~Pa} \cdot \mathrm{m}^{3} / \mathrm{s}$ \\
\hline 5 & $\begin{array}{c}\text { Positive } \\
\text { leakage rate of } \\
\text { valve plate }\end{array}$ & $<1.0 \times 10^{-10} \mathrm{~Pa} \cdot \mathrm{m}^{3} / \mathrm{s}$ & $\begin{array}{c}\text { The helium } \\
\text { method }\end{array}$ & $<1.0 \times 10^{-10} \mathrm{~Pa} \cdot \mathrm{m}^{3} / \mathrm{s}$ \\
\hline 6 & $\begin{array}{c}\text { The total } \\
\text { leakage rate }\end{array}$ & $<1.0 \times 10^{-10} \mathrm{~Pa} \cdot \mathrm{m}^{3} / \mathrm{s}$ & $\begin{array}{c}\text { The helium } \\
\text { method }\end{array}$ & $<1.0 \times 10^{-10} \mathrm{~Pa} \cdot \mathrm{m}^{3} / \mathrm{s}$ \\
\hline
\end{tabular}

\subsection{Valve installation leak rate test}

After the valve is installed on the space environment simulator, the installation leakage rate can be detected as described in 2.2. In order to improve efficiency, some procedures have been simplified. The specific leak detection process is as follows:

A) First make a preliminary judgment on the leakage rate at the connection between the valve seat and the simulator and the rough pumping line. That is, a rough pumping unit is used to vacuum the KM6 space simulator, and compared with the previous pumping time. If the time of pumping is not different from the previous time, we think that the leakage rate at the connection between the valve seat and the rough pumping line meets the requirements;

B) After the high vacuum system of the simulator is started, a leak detection system shall be established, as shown in Figure 2 below. Three low-temperature pumps and three TPH2200 molecular pumps shall be started for leak detection. The leak detector is connected in parallel with roots pump unit for shunt leak detection. The standard nominal value of leak hole is $2.0 \times 10^{-6} \mathrm{~Pa} \cdot \mathrm{m}^{3} / \mathrm{s}$, and its reaction value in the leak detection system is $1.20 \times 10^{-7} \rightarrow 3.30 \times 10^{-7}$, and the leak detection sensitivity is $1.9 \times 10^{-7} \mathrm{pa} \cdot \mathrm{m}^{3} / \mathrm{s}$.

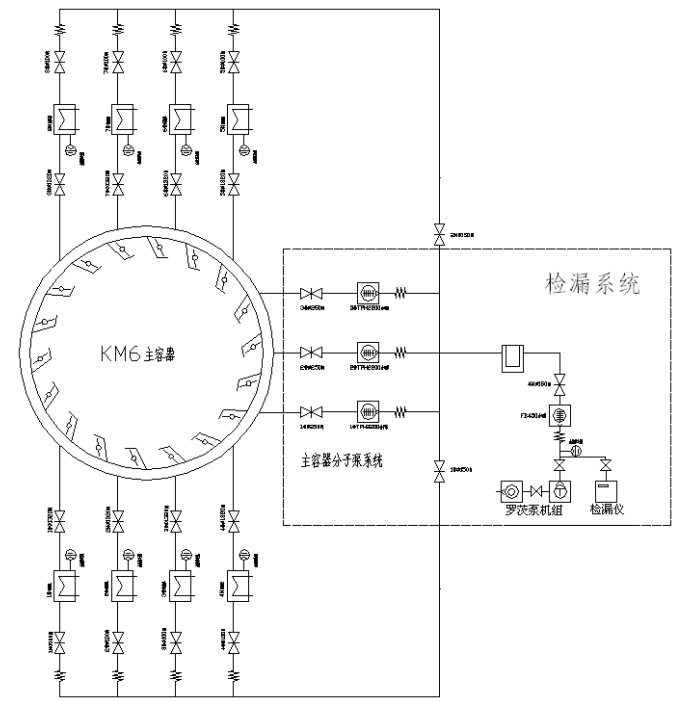

Figure 2 schematic diagram of leakage rate detection in valve installation

C) After the sensitivity test of the system is completed, helium cover method is first used to detect the leakage rate at the connection between the valve seat and the simulator; After completion, the forward sealing performance of the valve is reinspected. Helium mass spectrometry method was used to jet helium gas from the crude pumping pipe to the sealing valve plate;

D) Since the reverse sealing performance of valve plate has been tested before delivery, and what we need is the forward sealing performance of valve, the reverse sealing performance of valve has not been tested.

So far, valve installation leak rate detection has been completed, the specific results are shown in Table 2 below.

Table 2 Detection results of leakage rate in valve installation

\begin{tabular}{|c|c|c|c|c|}
\hline Number & Inspection items & $\begin{array}{c}\text { The technical } \\
\text { requirements }\end{array}$ & $\begin{array}{c}\text { Inspection } \\
\text { methods }\end{array}$ & Inspection results \\
\hline 1 & $\begin{array}{c}\text { The connection } \\
\text { between the seat } \\
\text { and the rough } \\
\text { pumping line }\end{array}$ & 2 hours and 40 minutes & $\begin{array}{c}\text { Compared with } \\
\text { the rough } \\
\text { drawing time }\end{array}$ & 2 hours 43 minutes \\
\hline 2 & $\begin{array}{c}\text { Connection } \\
\text { between seat }\end{array}$ & $<1.0 \times 10^{-6} \mathrm{~Pa} \cdot \mathrm{m}^{3} / \mathrm{s}$ & $\begin{array}{c}\text { The helium } \\
\text { method }\end{array}$ & $\begin{array}{c}<1.9 \times 10^{-7} \\
\mathrm{~Pa} \cdot \mathrm{m}^{3} / \mathrm{s}\end{array}$ \\
\hline
\end{tabular}




\begin{tabular}{|c|c|c|c|c|}
\hline & and simulator & & & \\
\hline 3 & $\begin{array}{l}\text { Positive leakage } \\
\text { rate of valve } \\
\text { plate }\end{array}$ & $<1.0 \times 10^{-10} \mathrm{~Pa} \cdot \mathrm{m}^{3} / \mathrm{s}$ & $\begin{array}{c}\text { Recheck by } \\
\text { blowing method }\end{array}$ & $\begin{array}{l}\text { No reaction, } \\
\text { considered as the } \\
\text { valve factory } \\
\text { leakage rate }\end{array}$ \\
\hline 4 & $\begin{array}{c}\text { Reverse leakage } \\
\text { rate of valve } \\
\text { plate }\end{array}$ & $<1.0 \times 10^{-10} \mathrm{~Pa} \cdot \mathrm{m}^{3} / \mathrm{s}$ & Without recheck & $\begin{array}{l}\text { Considered as the } \\
\text { leakage rate of valve }\end{array}$ \\
\hline
\end{tabular}

\section{4 conclusion}

The leakage rate of the rough pumping valve of the space environment simulator has a direct influence on the vacuum degree of the container, so it is very necessary to detect the leakage rate. Valve leakage rate detection is generally divided into two stages, factory leakage rate detection and valve installation leakage rate detection. This paper briefly introduces the leakage rate detection method of the rough pumping valve of the space environment simulator in these two stages, and applies it to the rough pumping valve of the KM6 space environment simulator, and obtains good results.

\section{References}

1. DA Daoan. Space vacuum technology[M]. Beijing: China Astronautic Publishing House, 1995: 7.

2. ZHANG Lei, WANG Junwei, FU Chunyu. Configuration strategy of vacuum system in largescale space environment simulator[J]. Equipment Environmental Engineering, 2018, 15(6): 1-6.

3. XU Zhongxu, WANG Hongxing, GUAN Laishui. The analysis and solution of the abnormal vacuum degree in environment simulation equipment[J]. Vacuum, 2014, 51(5): 39-42.

4. WU Yue, E Dongmei, DU Peng, et al. The leak detection method of the joint of spacecraft capsule[J]. Vacuum, 2018, 55(6): 1-4.

5. WU Xiaojian, Yan Rongxin. Leak detection[M]. Beijing: China Machine Press, 2004: 99.

6. CAO Shencheng. Practical vacuum leak detection technology[M]. Beijing: Chemical Industry Press, 2010:107108.

7. WANG Chunming, ZHANG Mingda, SU Yuping. Discussion on leak detection method of vacuum application equipment[J]. Vacuum, 2019, 56(1): 52-55.

8. JIANG Yongming. Leak detection of the large space environmental simulation test equipment[J]. Vacuum \& Cryogenics, 2016, 22(3): 177-180. 